\title{
EIF5A2 predicts outcome in localised invasive bladder cancer and promotes bladder cancer cell aggressiveness in vitro and in vivo
}

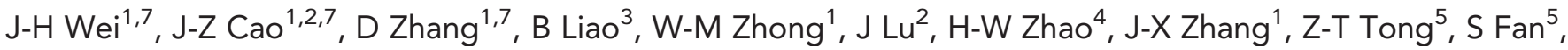

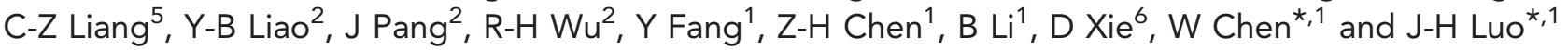 \\ ${ }^{1}$ Department of Urology, First Affiliated Hospital, Sun Yat-Sen University, Guangzhou, China; ${ }^{2}$ Department of Urology, Jiangmen \\ Hospital, Sun Yat-Sen University, Jiangmen, China; ${ }^{3}$ Department of Pathology, First Affiliated Hospital, Sun Yat-Sen University, \\ Guangzhou, China; ${ }^{4}$ Department of Urology, Yuhuangding Hospital, Qingdao University Medical College, Yantai, China; \\ ${ }^{5}$ Department of Urology, First Affiliated Hospital, Anhui Medical University, Hefei, China and ${ }^{6}$ State Key Laboratory of Oncology in \\ South China, Cancer Center, Sun Yat-Sen University, Guangzhou, China
}

Background: EIF5A2, eukaryotic translation initiation factor 5A2, is associated with several human cancers. In this study, we investigated the role of EIF5A2 in the metastatic potential of localised invasive bladder cancer (BC) and its underlying molecular mechanisms were explored.

Methods: The expression pattern of EIF5A2 in localised invasive BC was determined by immunohistochemistry. In addition, the function of EIF5A2 in BC and its underlying mechanisms were elucidated with a series of in vitro and in vivo assays.

Results: Overexpression of EIF5A2 was an independent predictor for poor metastasis-free survival of localised invasive BC patients treated with radical cystectomy. Knockdown of EIF5A2 inhibited BC cell migratory and invasive capacities in vitro and metastatic potential in vivo and reversed epithelial-mesenchymal transition (EMT), whereas overexpression of EIF5A2 promoted $\mathrm{BC}$ cells motility and invasiveness in vitro and metastatic potential in vivo and induced EMT. In addition, we found that ElF5A2 might activate TGF- $\beta 1$ expression to induce EMT and drive aggressiveness in BC cells. EIF5A2 stabilized STAT3 and stimulated nuclear localisation of STAT3, which resulted in increasing enrichment of STAT3 onto TGF- $\beta 1$ promoter to enhance the transcription of TGF- $\beta 1$.

Conclusions: EIF5A2 overexpression predicts tumour metastatic potential in patients with localised invasive BC treated with radical cystectomy. Furthermore, EIF5A2 elevated TGF- $\beta 1$ expression through STAT3 to induce EMT and promotes aggressiveness in BC.

Bladder cancer (BC) is one of the leading causes of morbidity and mortality in the United States and is the fourth most common cancer in men in the United States, with 54610 new cases diagnosed in 2013 (Siegel et al, 2013). Radical cystectomy is necessary in invasive $\mathrm{BC}$ and may have a significant impact on the quality of life of patients. However, only $23-46 \%$ patients who underwent radical cystectomy can survive for more than 5 years
(Pelucchi et al, 2006), which means that more than half of the invasive $\mathrm{BC}$ patients who underwent radical cystectomy died of tumour metastasis. Therefore, the high metastasis of $\mathrm{BC}$ after radical cystectomy surgery has always been the major obstacle in the enhancement of survival rate in clinical treatment. According to current studies, BC metastasis was believed to be a multistep process driven by the accumulation of genetic alterations

\footnotetext{
${ }^{\star}$ Correspondence: Professor J-H Luo; E-mail: luojunh@mail.sysu.edu.cn or Professor W Chen; E-mail: chenw3@mail.sysu.edu.cn ${ }^{7}$ These authors contributed equally to this work
} 
(Nguyen et al, 2009). The loss of tumour suppressor genes and activation of oncogenes are central events in the development and progression of BC (Pelucchi et al, 2006). Therefore, it is necessary to investigate the molecular mechanisms of the genes closely related to the metastasis of $\mathrm{BC}$ with the goal of improving the intervention of $\mathrm{BC}$.

The eukaryotic initiation factor 5A2 (EIF5A2) gene, located on chromosome 3q26, was first discovered in the primary ovarian cancer cell line in 2001 and has been classified as an oncogene (Guan et al, 2001). Then Guan et al (2004) demonstrated an oncogenic role of EIF5A2 in ovarian cancer tumorigenesis. Overexpression of EIF5A2 predicts poor prognosis in gastric adenocarcinomas (Marchet et al, 2007), colorectal cancer (Xie et al, 2008; Zhu et al, 2012), hepatocellular carcinomas (Tang et al, 2010), ovarian cancer (Yang et al, 2009) and non-small cell lung cancer (He et al, 2011). Further studies reveal that EIF5A2 stimulates cell cytoskeleton rearrangement through the activation of Rho/Rac GTPase to induce hepatocellular carcinoma invasiveness (Tang et al, 2010). In colorectal carcinoma, EIF5A2 upregulates metastasis-associated protein 1(MTA1) through $\mathrm{c}-\mathrm{myc}$ to induce EMT and promote aggressiveness (Zhu et al, 2012). Our previous studies demonstrated that EIF5A2 overexpression correlates with shortened survival of $\mathrm{BC}$ patients treated with radical cystectomy (Chen et al, 2009). To date, however, the function of EIF5A2 in localised invasive $\mathrm{BC}$ and its underlying molecular mechanisms are still unclear.

Herein, we report that overexpression of EIF5A2 in localised invasive $\mathrm{BC}$ is important in the acquisition of a metastatic phenotype. Knockdown of EIF5A2 in BC cells inhibits cell migration and invasion in vitro and metastatic potential in vivo and reversed EMT, whereas overexpression of EIF5A2 promotes $\mathrm{BC}$ cell migratory and invasive in vitro and metastatic potential in vivo and induced EMT. Overexpression of EIF5A2 in BC cells elevated the stability of STAT3 and stimulated nuclear localisation of STAT3, which resulted in increasing enrichment of STAT3 onto TGF- $\beta 1$ promoter to enhance its transcription. TGF- $\beta 1$ upregulation by EIF5A2 in BC cells was partly dependent on STAT3. Our results provide functional and mechanistic links between EIF5A2 and EMT in the aggressiveness of BC.

\section{MATERIALS AND METHODS}

Patients. On institutional review board approval, we identified 154 patients with localised invasive $\mathrm{BC}$ treated with radical cystectomy between 2002 and 2007 at First Affiliated Hospital, Jiangmen Hospital of Sun Yat-Sen University and Yuhuangding Hospital of Qingdao University Medical College. None of the patients received adjuvant therapy. Data collected from each patient included gender, age at diagnosis, grade, stage, and metastasis-free survival time. The histologic grade and stage were reassessed according to the 1973 WHO grading system and the 2009 TNM classification system, respectively. Localised invasive $\mathrm{BC}$ is defined as histologically verified pathologic tumour stage greater than or equal to 1 , no lymphatic metastasis and no distant metastasis disease (Stenzl et al, 2011). Metastasis-free survival was determined from the date of surgery to the date of the first clinical evidence of metastasis, and was censored at the date of death from other causes or the date of the last follow-up visit for survivors. Paraffin specimens were obtained by radical cystectomy, and 30 cases of normal bladder mucosa from adjacent nonneoplastic bladder tissue of the same BC patients were also obtained. Ten pairs of cancer tissues and adjacent normal bladder specimens were snap-frozen in chilled liquid nitrogen and stored at $-80^{\circ} \mathrm{C}$ until further processing. The study was approved by the medical ethics committee of each participating institute. No informed consent (written or verbal) was obtained for the use of the retrospective tissue samples from the patients within this study. Informed consent was not deemed necessary by the Ethics Committee, who waived the need for consent. All the samples were anonymous.

Tissue microarray construction and immunohistochemical evaluation. See Supplementary Materials and Methods (available online only) for details.

Western blotting. See Supplementary Materials and Methods (available online only) for details.

Cell cultures and stable transfectants. Human bladder transitional cell lines T24 and 5637 were purchased from the American Type Culture Collection (Rockville, MD, USA). The EJ and BIU-87 cells were kindly supplied by the Institute of Urology, Beijing Medical University (Beijing, China). Four BC cell lines-EJ (derived from an advanced grade IV transitional cell carcinoma), BIU-87 (established from the bladder papillary urothelial carcinoma (T1G2)), 5637 (derived from the primary grade II bladder carcinoma), and T24 (established from a highly malignant grade III human urinary bladder carcinoma) - were maintained in RPMI1640 supplemented with $10 \%$ fetal bovine serum. TGF- $\beta 1$ was purchased from PeproTech (Hamburg, Germany). Untreated controls received vehicle alone. The EIF5A2 complementary DNA (Fulengen, Guangzhou, China) was cloned into pcDNA3.1 plasmid. Cells were transfected with pcDNA-EIF5A2 or the control plasmid pcDNA3.1 $(+)$ using Lipofectamine 2000 (Invitrogen, Carlsbad, CA, USA) according to the manufacturer's instructions. For the establishment of the 5637-EIF5A2 cell line stably expressing EIF5A2, $48 \mathrm{~h}$ after transfection, the cells were split at a ratio of $1: 10$. Next, cells were maintained in Leibovitz's L-15 medium containing $200 \mu \mathrm{g} \mathrm{ml}^{-1}$ of G418 (Calbiochem, San Diego, CA, USA). After 6 weeks of selection, resistant colonies stably transfected with pcDNA-EIF5A2 (EIF5A2 expression vector) or pcDNA3.1 $(+)$ (empty vector) were pooled.

RNA interference. Short interfering RNA specifically against EIF5A2 (Tang et al, 2010), TGF- $\beta 1$ and STAT3 transfected into BC cells in 6-well plates using Lipofectamine 2000 reagent (Invitrogen) according to the manufacturer's instructions. The oligoribonucleotide sequence of short interference RNA to repress TGF- $\beta 1$ and STAT3 are listed as follows: TGF- $\beta 1$ sense: $5^{\prime}$-UGGU GAAGCGGAAGCGCAUUU-3'; TGF- $\beta 1$ antisense: $5^{\prime}$-AUGCGC UUCCGCUUCACCAUU-3'. STAT3 sense: $5^{\prime}$-GGAGAAGCAUC GUGAGUGAUU-3' STAT3 antisense: $5^{\prime}$-UCACUCACGAUGCU UCUCCUU- $3^{\prime}$. The sequence of human short hairpin RNA (shRNA) sequences to repress EIF5A2 expression (shEIF5A2) is $5^{\prime}$-GCTAGCAGCTTATCAGGAAGGAA-3'. Vector construction, lentivirus production and infection were performed as described previously (Zheng et al, 2012). Human BC EJ cells were infection with shEIF5A2 (EJ-shEIF5A2) and control scramble shRNA (EJ-scramble), respectively. The gene silencing effect was measured by western blotting $48 \mathrm{~h}$ post transfection.

RNA extraction, reverse transcription and quantitative PCR. See Supplementary Materials and Methods (available online only) for details.

Wounding healing and invasion assays. Cell migration was assessed by measuring the movement of cells into a wound - a scraped, a cellular area made by a $200 \mu$ l pipette tube. Wound closure was observed after $48 \mathrm{~h}$. Invasion assays were performed with 24-well BioCoat Matrigel Invasion Chambers (BD Biosciences, San Diego, CA, USA) according to the manufacturer's instructions. Briefly, $2 \times 10^{4}$ cells were seeded into $8 \mu \mathrm{m}$ pore inserts in triplicate wells and incubated for $24 \mathrm{~h}$. The invaded cells in lower filters were fixed in methanal and stained in crystal violet (Sigma, St Louis, MO, USA) followed by counting under microscope. All experiments were repeated three times and a representative result was presented. 
Immunofluorescence analysis. Cells were incubated with primary antibodies against E-cadherin, $\alpha$-catenin, vimentin, fibronectin (Santa Cruz Biotechnology, Santa Cruz, CA, USA, 1:100 dilution), EIF5A2 (Abnova, Jhongli, Taiwan, 1:100 dilution) or STAT3 (BD Biosciences, 1:100 dilution) overnight at $4{ }^{\circ} \mathrm{C}$ and then incubated with rhodamine-conjugated or FITC-conjugated goat antibodies against rabbit or mouse IgG (Jackson Immuno-Research Laboratories, Westgrove, PA, USA). The coverslips were counterstained with DAPI (Vector Laboratories, Burlingame, CA, USA) and imaged with a confocal laser scanning microscope Olympus FV1000 (Tokyo, Japan).

Tumour metastasis in nude mice. Female BALB/c-nu/nu athymic mice (4-5 weeks old), purchased from Shanghai Slac Laboratory Animal (Shanghai, China), were kept under specific pathogen-free conditions and cared for in accordance with the guidelines of the laboratory animal ethics committee of Sun Yat-Sen University. Eight mice in each experimental group were injected with EJ-scramble, EJ-shEIF5A2, 5637-EIF5A2 and 5637-vector cells separately. Briefly, $2 \times 10^{5}$ cells were injected intravenously through the tail vein into each mouse in a laminar flow cabinet. Six weeks after cell injection, mice were killed and examined. All the procedures are in accordance with the guidelines of the laboratory animal ethics committee of Sun Yat-Sen University.

Chromatin immunoprecipitation (ChIP) assays. See Supplementary Materials and Methods (available online only) for details.

Dual luciferase reporter assay. Dual luciferase reporter assay was performed as described previously (Tong et al, 2012) with slight modification. Briefly, PCR was performed to amplify human TGF$\beta 1$ promoter sequences $(-3363$ to +110$)$. The PCR product was subcloned into the pGL3 luciferase reporter construct (Promega, Madison, WI, USA). The treated 5637 cells were lysed, and the activities of the firefly and Renilla luciferases were analysed using a dual luciferase assay kit (Promega) according to the manufacturer's instructions. All reporter gene assays were performed in triplicate and repeated twice. The results were expressed as the mean \pm s.e.

Statistical analysis. Groups were compared using $\lambda^{2}$ test for categorical variables. Survival curves were estimated using the Kaplan-Meier method. The univariate Cox proportional regression hazard model was used to analyse the correlation between variables and clinical outcomes. Multivariate survival analysis was performed on all parameters that were significant on univariate analysis using the Cox regression model. The predictive accuracy of prognostic factors was determined using time-dependent receiver operating characteristic (ROC) analysis for censored data, and the area under the curve (AUC) at 5 year was used to measure predictive accuracy. $P$-values $<0.05$ were considered significant. $\mathrm{R}$ software version 2.7.1 (R Foundation for Statistical Computing, Vienna, Austria) was used for time-dependent ROC curve analysis. SPSS software (SPSS Standard version 16.0; SPSS, Chicago, IL, USA) was used for all other calculations.

\section{RESULTS}

The expression of EIF5A2 in localised invasive BC. To investigate the expression status of EIF5A2 in $\mathrm{BC}$, we conducted western blotting in 10 fresh $\mathrm{BC}$ tissues $(\mathrm{T})$ with their adjacent normal bladder tissues $(\mathrm{N})$. As shown in Figure 1A, EIF5A2 protein levels were elevated in $\mathrm{BC}$ tissues compared with adjacent normal bladder tissues. Consistent with these results, immunohistochemical (IHC) analysis revealed a similar trend in BC and the corresponding adjacent noncancerous tissues. Immunohistochemical staining of EIF5A2 in representative samples of BC and normal bladder mucosal tissues is shown in Figure 1B-D. The clinicopathological characteristics of the 154 patients studied were summarised in Table 1. Using the criteria described above, we found overexpression of EIF5A2 in $63(40.9 \%)$ BC. No significant correlation was found between EIF5A2 expression and patient age or gender, or tumour grade, stage, or multiplicity $(P>0.05$, Table 1$)$.

Relationship between EIF5A2 expression and localised invasive BC patient clinicopathologic features and survival. A total of $37.0 \%(57 / 154)$ of patients showed tumour metastasis after an average of 31.6 months. Univariate Cox regression analysis identified EIF5A2 expression, pathological stage, and tumour grade to have a significant impact on metastasis-free survival $(P=0.006$, 0.006, and 0.009, respectively; Table 2). Other clinicopathological variables, including age, gender, and tumour multiplicity, showed no significant correlation with metastasis-free survival $(P>0.05$, Table 2$)$. The parameters that were significant in univariate analysis were further examined in Cox regression multivariate analysis. The results showed that the expression of EIF5A2 $(P=0.006$, Figure $1 \mathrm{E})$, tumour stage $(P=0.007)$, and tumour grade $(P=0.008)$ were independent predictors of tumour metastasis (Table 2).

In addition, we constructed a prognostic model combining three independent prognostic factors (EIF5A2, stage and grade) by Cox proportional hazards regression. Time-dependent ROC curve was used to compare the prognostic validity of the combined model with each factor alone model. As showed in Figure 1F, the model combining EIF5A2, grade, and stage (AUC at 5 year: $0.803 ; 95 \%$ CI: $0.671-0.940)$ had a better prognostic value than EIF5A2 alone model (AUC at 5 year: 0.640; 95\% CI: $0.543-0.736 ; P=0.012$ ), tumour grade alone model (AUC at 5 year: 0.640 ; $95 \%$ CI: $0.520-$ $0.754 ; P=0.016$ ), and stage alone model (AUC at 5 year: 0.656 ; 95\% CI: $0.526-0.802 ; P=0.002)$. Therefore, the expression of EIF5A2 might add prognostic value to the staging and grading system of BC.

Knockdown of EIF5A2 inhibited BC cell migration and invasion in vitro and metastatic potential in vivo. As the overexpression of EIF5A2 examined by immunohistochemistry was positively associated with $\mathrm{BC}$ metastasis, to investigate the impact of EIF5A2 on $\mathrm{BC}$ cell invasiveness, we analysed EIF5A2 expression in four tumour-derived BC cell lines by western blotting. T24 and EJ cell lines showed relative higher endogenous EIF5A2 expression compared with 5637 and BIU-87 cell lines both at mRNA and protein levels (Figure 2A). Both siRNA could efficiently knockdown endogenous EIF5A2 in BC cells (Figure 2B). The results showed that knockdown of EIF5A2 caused an apparent suppression of cell migration in both T24 and EJ cell lines using a wound-healing assay (Figure 2C). Matrigel invasion assays also demonstrated that ablation of endogenous EIF5A2 markedly reduced the invasive capacity of both T24 and EJ cell lines (Figure 2D). To investigate the in vivo effect of EIF5A2 knockdown on metastasis, we used an experimental metastasis assay in which we injected EJ-scramble and EJ-shEIF5A2 into the lateral tail vein of athymic nude mice (eight mice per group). As showed in Figure 2E, the mice injected with EJ-shEIF5A2 cells formed fewer nodes per lung than the mice injected with control shRNA cells $(2.875 \pm 2.850$ versus $13.5 \pm 5.632, P<0.001$, Mann-Whitney test). Histological studies confirmed that the lesions were caused by extravasation and subsequent tumour growth of EJ cells into the lungs (Figure 2F).

Overexpression of EIF5A2 promoted migration and invasion of $\mathrm{BC}$ cells in vitro and metastatic potential in vivo. To determine whether overexpression of EIF5A2 could enhance the invasive capacity of BC cells, we constructed a 5637-EIF5A2 cell line, which overexpressed EIF5A2 as demonstrated by western blotting and qPCR (Figure 3A). Wound-healing assay demonstrated that overexpression of EIF5A2 enhanced 5637 cell migration at the edge of exposed regions (Figure $3 \mathrm{~B}$ ). The matrigel invasion assay 


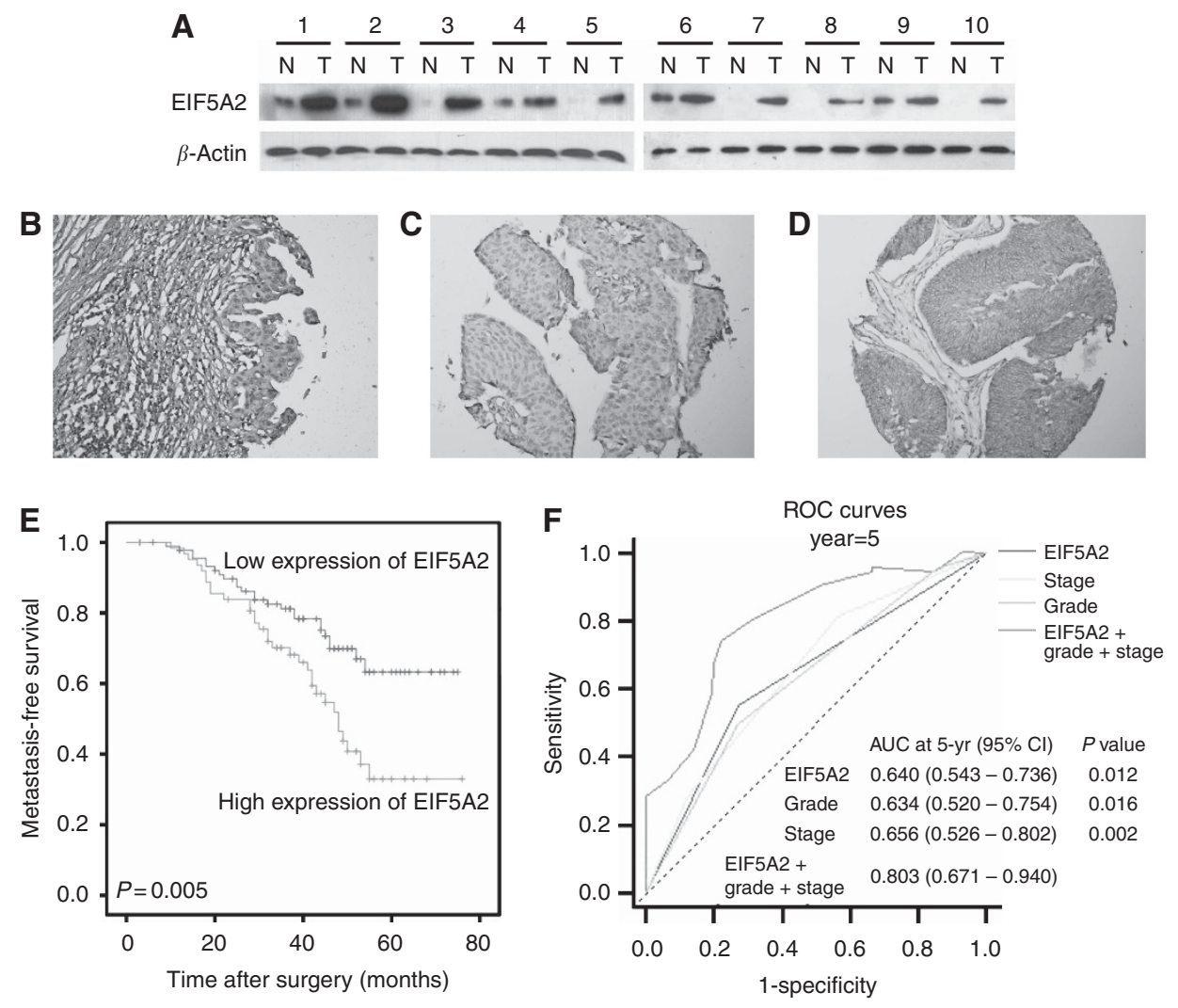

Figure 1. Western blotting and IHC assay of the expression pattern of EIF5A2 in BC tissues (A) western blotting analysis of EIF5A2 protein expression in pairs of matched BC (T) and adjacent noncancerous tissues (N). (B) Representative image of negative EIF5A2 IHC staining in normal bladder tissues. Representative image of normal expression (C), overexpression (D) EIF5A2 IHC staining in BC tissues are shown. (E) Kaplan-Meier survival analysis according to EIF5A2 expression in 154 patients with BC (log-rank test). Probability of survival of patients: normal expression of EIF5A2, $N=91$; overexpression of EIF5A2, $N=63(P=0.005)$. (F) Comparisons of the predictive accuracy by the combined EIF5A2, grade and stage model, the EIF5A2 alone model, the grade alone model, and the stage alone model. P-values show the AUC at 5 year for the combined EIF5A2, grade, and stage model versus the AUC at 5 year for the EIF5A2 alone model, the grade alone model, or the stage alone model.

\begin{tabular}{|c|c|c|c|c|}
\hline & & \multicolumn{2}{|c|}{ EIF5A2 protein } & \multirow[b]{2}{*}{$\boldsymbol{P}$-value ${ }^{a}$} \\
\hline Viables & Case & $\begin{array}{c}\text { Normal } \\
\text { expression }\end{array}$ & $\begin{array}{c}\text { Over- } \\
\text { expression }\end{array}$ & \\
\hline Age & & & & 0.456 \\
\hline $\begin{array}{l}\leqslant 60 \text { years } \\
>60 \text { years }\end{array}$ & $\begin{array}{l}74 \\
80\end{array}$ & $\begin{array}{l}46(62.2 \%) \\
45(56.3 \%)\end{array}$ & $\begin{array}{l}28(37.8 \%) \\
35(43.7 \%)\end{array}$ & \\
\hline Gender & & & & 0.598 \\
\hline $\begin{array}{l}\text { Male } \\
\text { Female }\end{array}$ & $\begin{array}{r}124 \\
30\end{array}$ & $\begin{array}{l}72(58.1 \%) \\
19(63.3 \%)\end{array}$ & $\begin{array}{l}52(41.9 \%) \\
11(36.7 \%)\end{array}$ & \\
\hline Grade & & & & 0.700 \\
\hline $\begin{array}{l}\mathrm{G} 1 \\
\mathrm{G} 2 \\
\mathrm{G} 3\end{array}$ & $\begin{array}{l}15 \\
80 \\
59\end{array}$ & $\begin{array}{l}10(66.7 \%) \\
45(56.3 \%) \\
36(61.0 \%)\end{array}$ & $\begin{array}{r}5 \text { (33.3\%) } \\
35(43.7 \%) \\
23(39.0 \%)\end{array}$ & \\
\hline Pathological stage & & & & 0.646 \\
\hline $\begin{array}{l}\text { T1 NO MO } \\
\text { T2 NO MO } \\
\text { T3/4NO MO }\end{array}$ & $\begin{array}{l}48 \\
74 \\
32\end{array}$ & $\begin{array}{l}31 \text { (64.6\%) } \\
42(56.8 \%) \\
18(56.3 \%)\end{array}$ & $\begin{array}{l}17 \text { (35.4\%) } \\
32(43.2 \%) \\
14(43.7 \%)\end{array}$ & \\
\hline Multiplicity & & & & 0.940 \\
\hline $\begin{array}{l}\text { Single } \\
\text { Multiple }\end{array}$ & $\begin{array}{l}63 \\
91\end{array}$ & $\begin{array}{l}37(58.7 \%) \\
54(59.3 \%)\end{array}$ & $\begin{array}{l}26(41.3 \%) \\
37(40.7 \%)\end{array}$ & \\
\hline $\begin{array}{l}\text { Abbreviations: } \mathrm{BC}=\mathrm{b} \\
\mathrm{a}_{\lambda^{2}} \text { test. }\end{array}$ & an & $5 \mathrm{~A} 2=$ eukar & tiation factor & \\
\hline
\end{tabular}

Table 2. Univariate and multivariate Cox regression analysis on the contribution of various potential prognostic parameters to metastasisfree survival of patients with $B C$

\begin{tabular}{|l|l|l|l|c|}
\hline Parameters & Categories & P-value & HR & $95 \%$ Cl \\
\hline Univariate Cox regression analysis \\
\hline EIF expression & Normal vs over & $\mathbf{0 . 0 0 6}$ & 2.082 & $1.233-3.517$ \\
Gender & Male vs female & 0.677 & 1.141 & $0.614-2.122$ \\
Age (years) & $\leqslant 60$ vs $>60$ & 0.890 & 0.964 & $0.573-1.621$ \\
Pathological stage & T1 vs T2 vs T3/4 & $\mathbf{0 . 0 0 6}$ & 1.667 & $1.157-2.402$ \\
WHO grade & G1 vs G2 vs G3 & $\mathbf{0 . 0 0 9}$ & 1.793 & $1.156-2.782$ \\
Multiplicity & Uni-vs multifocal & 0.061 & 0.608 & $0.362-1.023$ \\
\hline
\end{tabular}

\section{Multivariate Cox regression analysis}

\begin{tabular}{|l|l|l|l|l|}
\hline EIF expression & Normal vs over & $\mathbf{0 . 0 0 6}$ & 1.905 & $1.206-3.009$ \\
Pathological stage & T1 vs T2 vs T3/4 & $\mathbf{0 . 0 0 7}$ & 1.634 & $1.143-2.337$ \\
WHO grade & G1 vs G2 vs G3 & $\mathbf{0 . 0 0 8}$ & 2.048 & $1.210-3.468$ \\
\hline
\end{tabular}

Abbreviations: $\mathrm{BC}=$ bladder cancer; $\mathrm{Cl}=$ confidence interval; $\mathrm{EIF}=$ eukaryotic initiation factor; $\mathrm{HR}=$ hazard ratio; $\mathrm{WHO}=$ World Health Organization. Significant $P$-values $<0.05$ are shown in bold.

showed that 5637-EIF5A2 cells had significantly increased invasive capacity, compared with our control 5637-vector cells (Figure 3C).

Simultaneously, the mice injected with 5637-vector cells formed fewer nodes per lung than the mice injected with 5637-EIF5A2 cells (Figure 3D and E). Our data indicated that EIF5A2 promoted $\mathrm{BC}$ cells aggressiveness in vitro and in vivo. 
A

EJ $\quad$ T24 $5637 \quad$ BIU-87
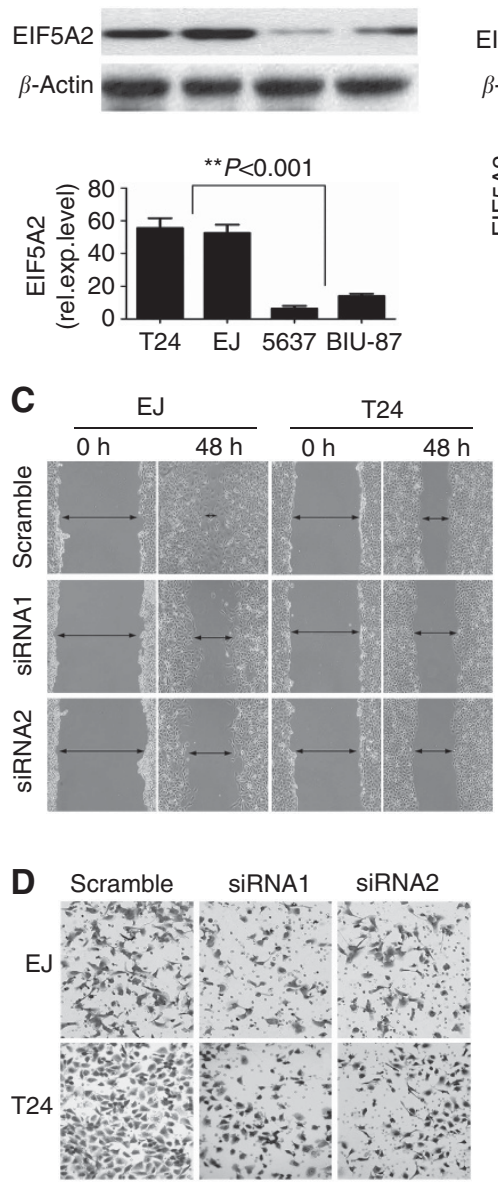

EJ 124
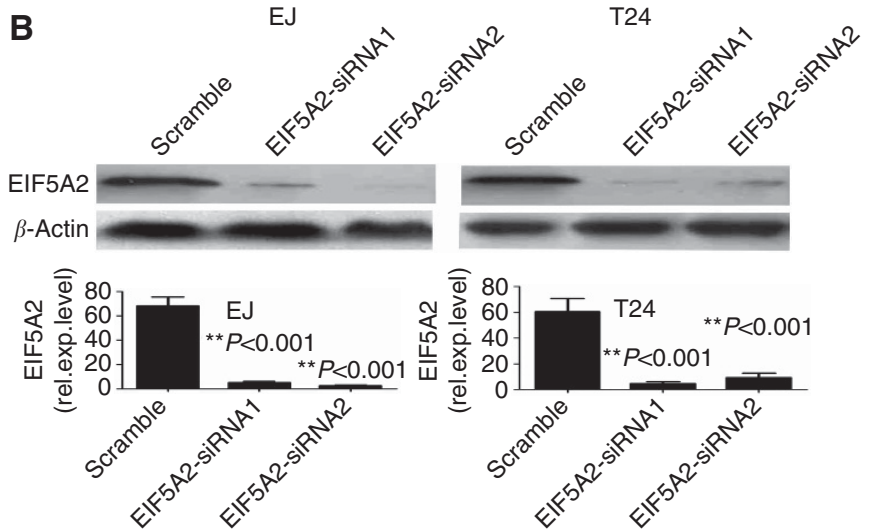
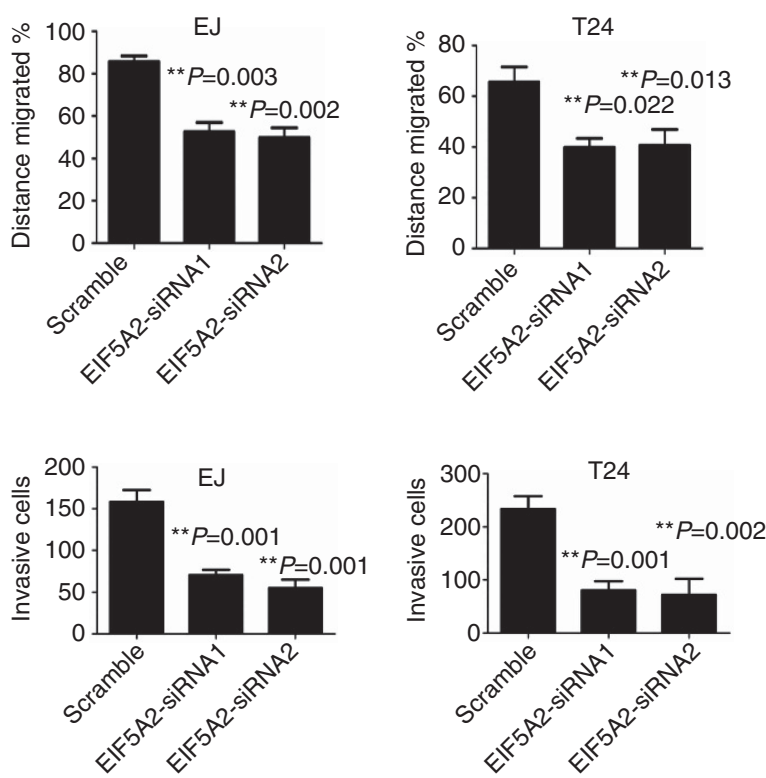

E
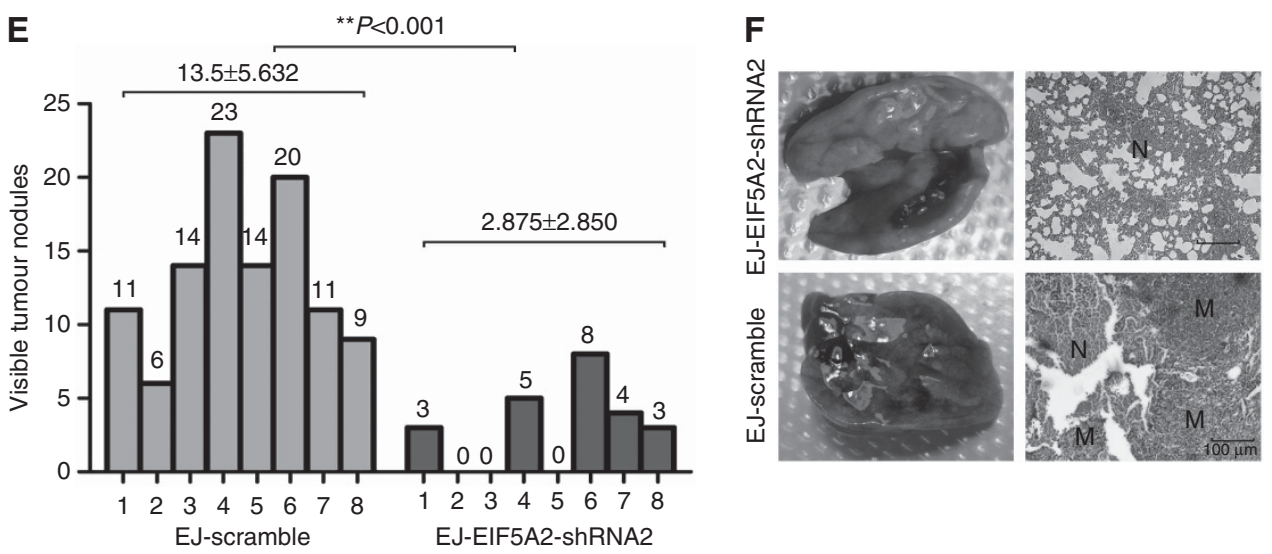

Figure 2. Suppression of EIF5A2 inhibits the migration and invasion ability of bladder cells in vitro and metastatic potential in vivo. (A) Western blotting and GPCR analyses of BC cell lines showing endogenous EIF5A2 expression. (B) Suppression of EIF5A2 in bladder cell lines completely eliminated EIF5A2 protein expression (upper panel). EIF5A2 mRNA levels (normalised to GAPDH) determined by qPCR in the EIF5A2 knockdown cells were significantly reduced (lower panel). (C) Suppression of EIF5A2 dramatically reduced the migration capacity of the cells as determined by a wound-healing assay. (D) Suppression of EIF5A2 significantly reduced the cells' invasion capacity in a transwell assay. (E) The number of nodules were qualified on lungs of athymic mice ( $N=8$ per group) 6 weeks after tail vein injection of EJ-shEIF5A2 (red bars) and EJ-scramble cells (blue bars). The nodules were examined under an anatomical microscope. ${ }^{\star \star} P<0.001$; Mann-Whitney test (F) Left panel: representative metastatic nodules on the surface of the lung of athymic mice. Right panel: H\&E staining was performed on serial sections of metastatic tumours $(\mathrm{M})$ and normal $(\mathrm{N})$ lung. Original magnification, $\times 200$. The full colour version of this figure is available at British Journal of Cancer online.

EIF5A2 regulated epithelial-mesenchymal transition in $\mathrm{BC}$ cells. As our recent study provided evidence that overexpression of EIF5A2 in HCC (Tang et al, 2010) and CRC (Zhu et al, 2012) cells resulted in an enhancement of EMT, we wondered if EIF5A2 also induces EMT in BC cells. In this study, after the silence of EIF5A2 in T24 and EJ cells, the expression levels of E-cadherin and 
$\alpha$-catenin were elevated while the levels of vimentin and fibronectin decreased by western blotting (Figure 4A). On the contrary, after overexpression of EIF5A2 in 5637 cells, the levels of E-cadherin and $\alpha$-catenin downregulated, whereas the levels of vimentin and fibronectin upregulated, as evidenced by both western blotting (Figure 4B) and immunofluorescence staining assays (Figure 4C).

In addition, IHC staining of EMT markers (E-cadherin, $\alpha$-catenin, vimentin and fibronectin) in our cohort of BC tissue microarray (TMA) tissues was utilised to analyse the EIF5A2 and EMT markers expression patterns in BC. Consistently, our IHC analysis in BC TMA samples further confirmed that EIF5A2 expression level positively correlated to the expression levels of vimentin and fibronectin, and inversely correlated to the expression levels of E-cadherin and $\alpha$-catenin (Supplementary Table S1, available online only). Figure $4 \mathrm{D}$ shows the representative immunohistochemistry results.

A

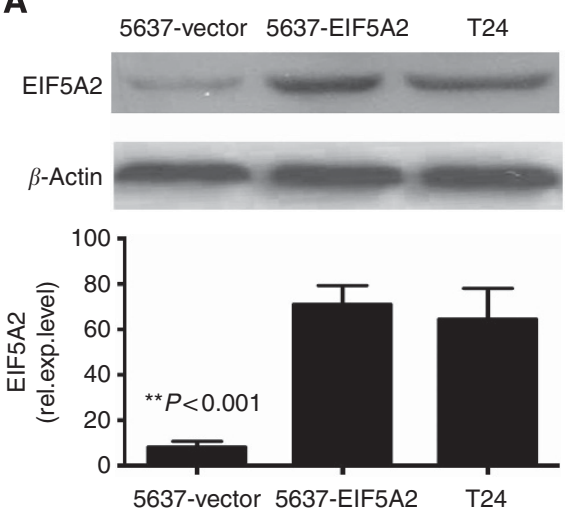

C

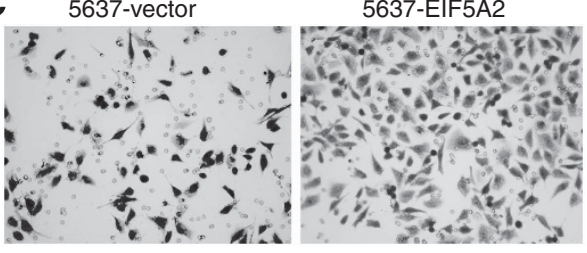

D
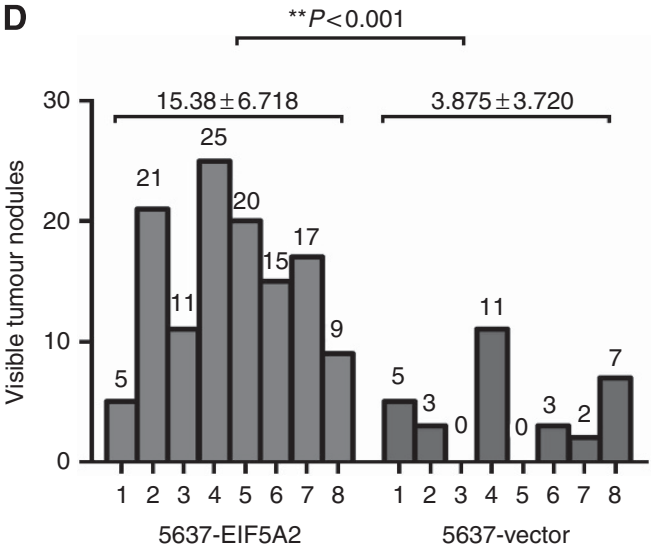

EIF5A2 upregulated TGF- $\beta 1$ to induce EMT and promote aggressiveness in BC cells. To obtain further insight into the molecular mechanisms of EIF5A2 in BC cell aggressiveness, messenger RNA expression profiles of EJ-shEIF5A2 cells were compared with those of control EJ-scramble cells using a human tumour metastasis $\mathrm{RT}^{2}$ profiler PCR array containing 84 cell metastasis-related genes. The results indicated that E-cadherin (i.e. cadherin 1 ), CTNNA1, TGF- $\beta 1$, TIMP2, TIMP3 and TIMP4 genes showed more than a two times change in mRNA levels. (Figure 5A and Supplementary Table S2, available online only). Subsequently, these downstream targets were selected and further validated by a western blotting assay. Consistent with those of mRNA expression in real-time PCR array, decreased TGF- $\beta 1$ and increased E-cadherin and CTNNA1 in protein levels were examined by western blotting in EIF5A2 knockdown EJ cells (Figure $5 \mathrm{~B}$ ). To investigate whether TGF- $\beta 1$ is required for EIF5A2-induced BC cell EMT and invasiveness, we conducted

B
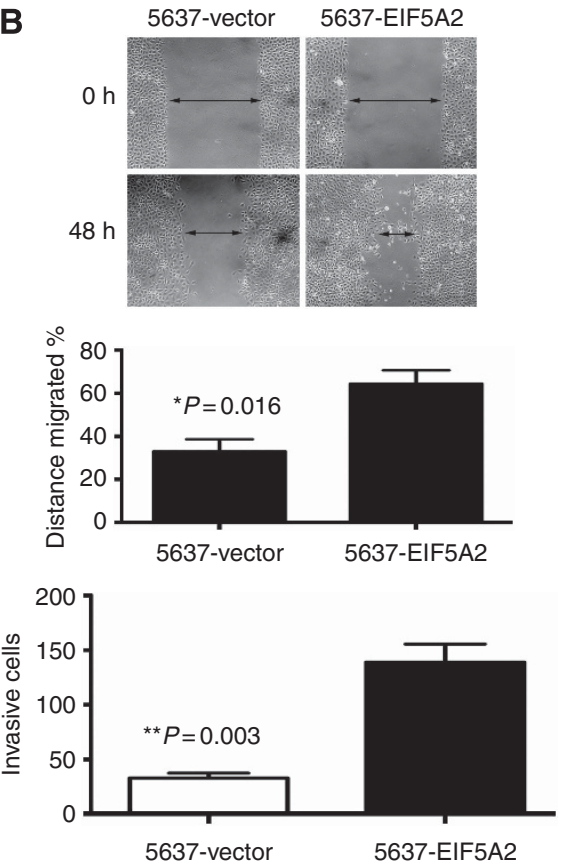

$\mathbf{E}$
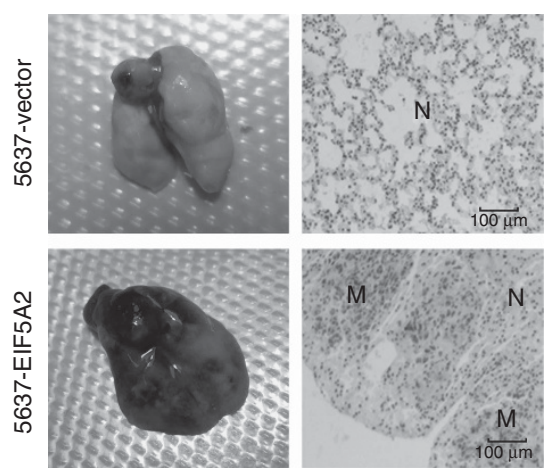

Figure 3. Overexpression of EIF5A2 promotes 5637 cells migration and invasion in vitro and in vivo. (A) Expression of EIF5A2 was substantially decteded in 5637-EIF5A2 cells compared with that in 5637-vector cells and T24 cells by western blotting and qPCR. (B) Ectopic overexpression of EIF5A2 enhanced the migration ability of the cells as determined by a wound-healing assay. (C) Overexpression of EIF5A2 enhanced 5637 cell invasion in a transwell assay. ${ }^{\star} P=0.003$; independent Student's $t$-test (D) The number of nodules were qualified on lungs of athymic mice ( $N=8$ per group) 6 weeks after tail vein injection of 5637-vector (red bars) and 5637-EIF5A2 cells (blue bars). The nodules were examined under an anatomical microscope. ${ }^{\star \star} P<0.001$; Mann-Whitney test $(E)$ Left panel: representative metastatic nodules on the surface of the lung of athymic mice. Right panel: H\&E staining was performed on serial sections of metastatic tumours $(\mathrm{M})$ and normal $(\mathrm{N})$ lung. Original magnification, $\times 200$. The full colour version of this figure is available at British Journal of Cancer online. 

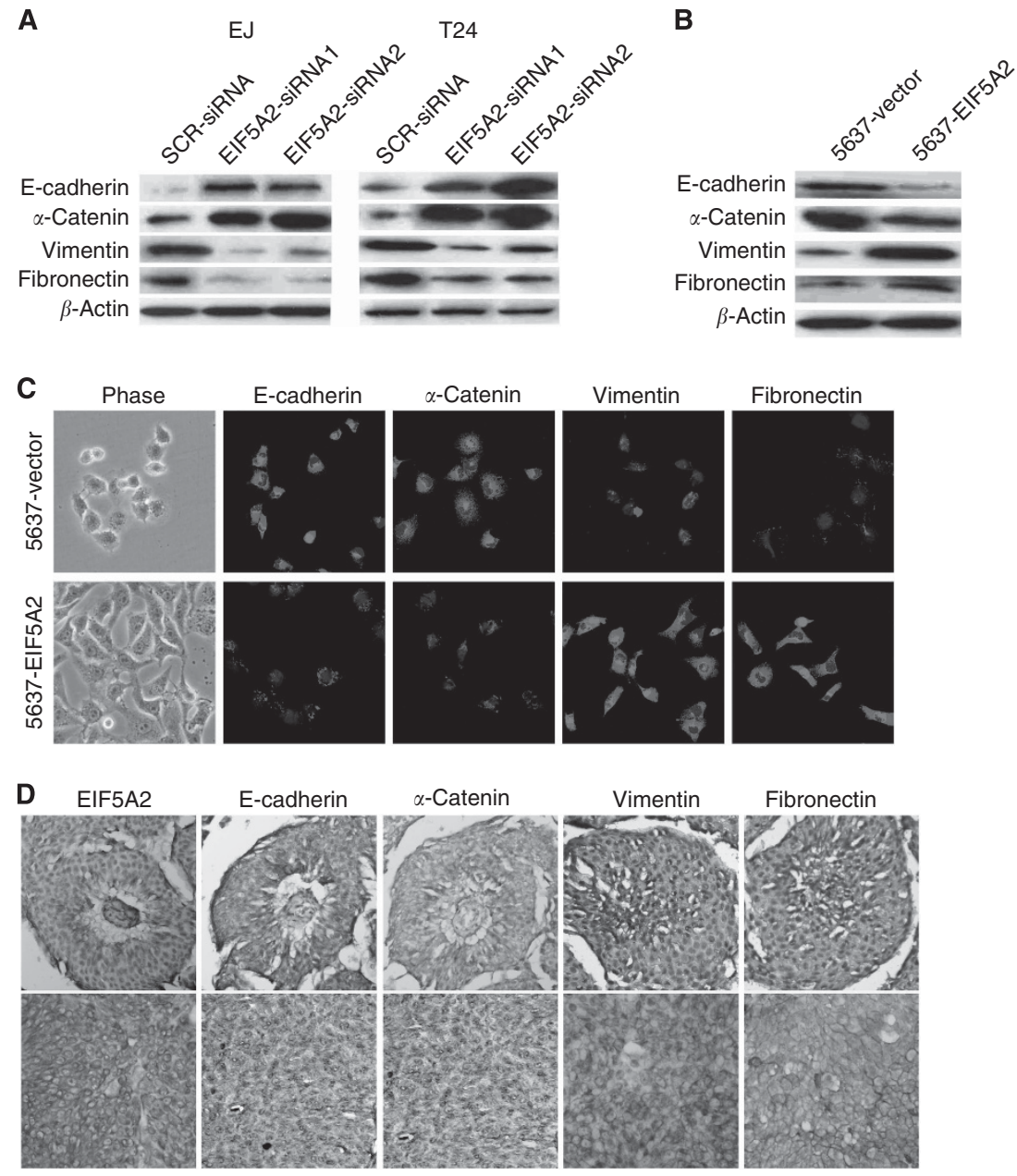

Figure 4. EIF5A2 induced BC cells EMT. (A) Knockdown of EIF5A2 in T24 and EJ cells resulted in upregulation of epithelial markers (E-cadherin and $\alpha$-catenin) and downregulation of mesenchymal markers (vimentin and fibronectin) by western blotting. (B) Western blotting assay shows decreased levels of the epithelial markers (E-cadherin and $\alpha$-catenin) and increased levels of the mesenchymal markers (fibronectin and vimentin) in 5637-EIF5A2 cells compared with that in 5637-vector cells. (C) Immunofluorescence staining shows a downregulated expression of E-cadherin and $\alpha$-catenin and an upregulated expression of vimentin and fibronectin in 5637-EIF5A2 cells in vitro. (D) Continuous sections of human BC TMA tissues were subjected to IHC staining. Normal expression of ElF5A2 in case 1 was accompanied by absence of vimentin and fibronectin but elevated levels of E-cadherin and $\alpha$-catenin (upper panel). Overexpression of EIF5A2 in case 2 was accompanied by elevated levels of vimentin and fibronectin but an absence of E-cadherin and $\alpha$-catenin (lower panel). Original magnification, $\times 200$.

RNA interference to knockdown TGF- $\beta 1$ expression in 5637EIF5A2 cells. After siTGF- $\beta 1$ treatment, EIF5A2-induced EMT was significantly inhibited (Figure $5 \mathrm{C}$ and $\mathrm{F}$ ). In addition, woundhealing and matrigel invasion assays showed that the migratory and invasive capacities of 5637-EIF5A2 cells were all dramatically inhibited after the silencing of TGF- $\beta 1$ (Figure $5 \mathrm{D}$ and $\mathrm{E}$ ). In contrast, TGF- $\beta 1$ introduction into EIF5A2-silenced T24 and EJ cells could restore their aggressive phenotype (see Supplementary Figure S1, available online only). These data, taken together, provided evidence that TGF- $\beta 1$ was responsible for the EIF5A2induced EMT and invasiveness in BC cells.

EIF5A2 stabilized STAT3 and stimulated nucleus localisation of STAT3 to augment enrichment of STAT3 onto TGF- $\beta 1$ promoter. TGF- $\beta 1$ has been shown to be regulated by transcription factors such as NF- $\kappa$ B (Lin et al, 2010), Sp1 (Kim et al, 1998), androgen receptor (AR) (Qi et al, 2008), upstream stimulatory factor 1 (USF1) (Weigert et al, 2004) and signal transducer and activator of transcription 3 (STAT3) (Ogata et al, 2006). We wondered whether EIF5A2-mediated TGF- $\beta 1$ upregulation is associated with these transcription factors in BC cells. As anticipated, the ChIP results demonstrated that in the 5637EIF5A2 cells, the enrichment of STAT3 was substantially enhanced, however, we did not find alternative recruitment of NF- $\kappa \mathrm{B}, \mathrm{Sp} 1, \mathrm{AR}$ and USF1 compared with that in control 5637vector cells (Figure 6A). At the same time, western blotting revealed that, compared with vector cells, expression of STAT3 significantly increased in 5637-EIF5A2 cells. However, real-time PCR shows no significant change in STAT3 mRNA (Figure 6B), suggesting that modulation of STAT3 expression might be due to posttranslational modification. To assess the effect of EIF5A2 on STAT3 stability, protein half-life of STAT3 was estimated by treating with $20 \mu \mathrm{M}$ cycloheximide for the indicated times. As showed in Figure 6C, the half-life of STAT3 was determined to be $\sim 16 \mathrm{~h}$ in 5637 -vector cells, which is consistent with a previous report (Jain et al, 2012). However, its half-life dramatically increased to more than $24 \mathrm{~h}$ in 5637-EIF5A2 cells. On the other hand, knockdown of EIF5A2 expression reduced the half-life of STAT3 protein in T24 cells. At the same time, immunofluorescence staining revealed EIF5A2 also affected the STAT3 
A

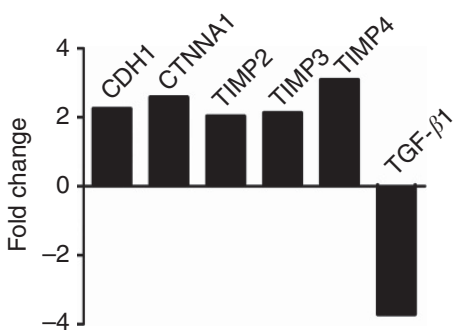

B

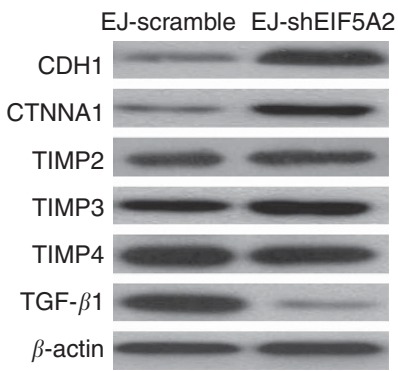

C

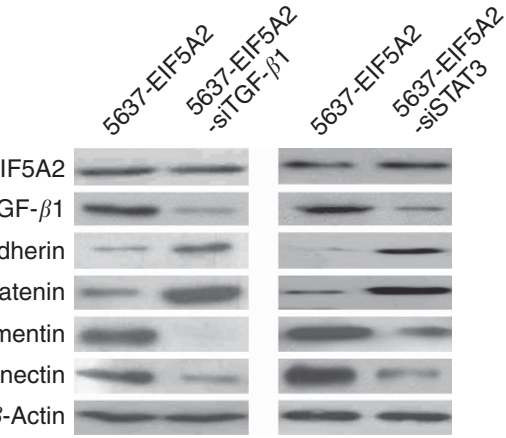

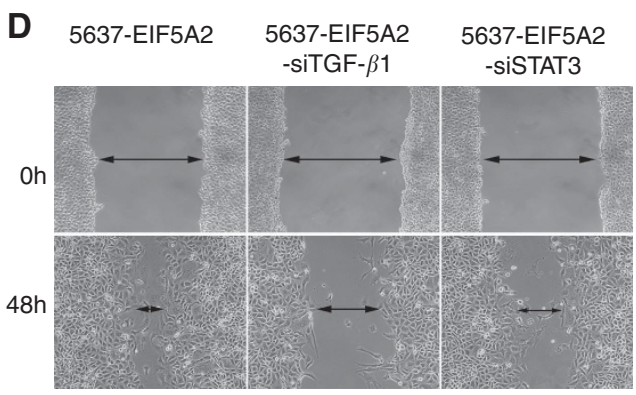

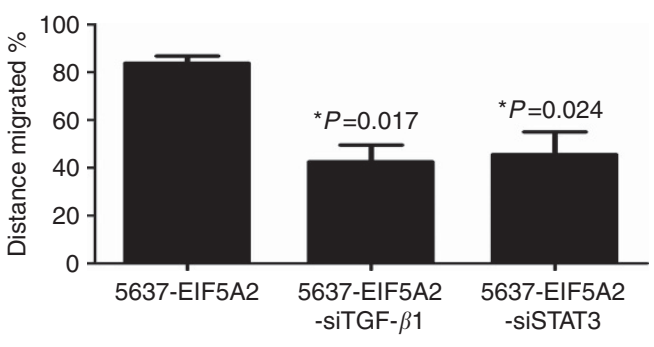

E
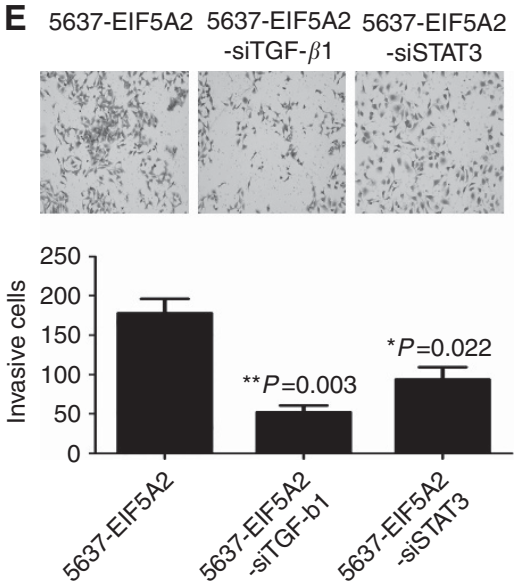

$\mathbf{F}$

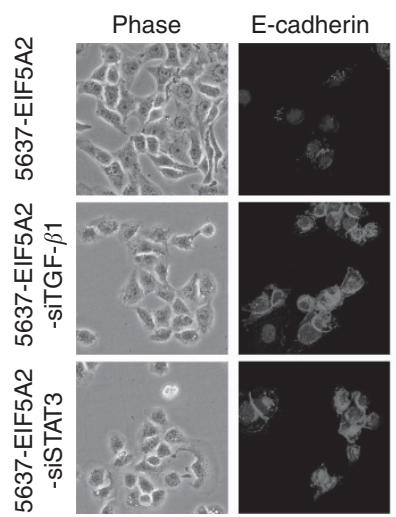

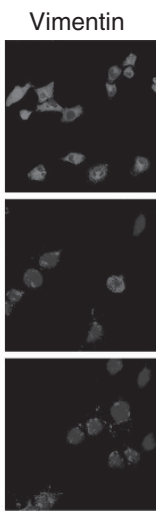

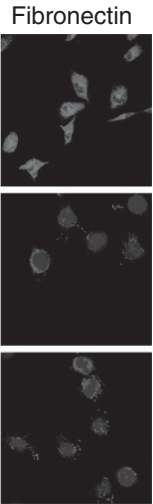

Figure 5. EIF5A2 promoted BC cell aggressiveness by upregulation of TGF- $\beta 1$ through STAT3. (A) The six genes, CDH1, CTNNA1, TIMP2, TIMP3, TIMP4 and TGF- $\beta 1$, showed more than a two times mRNA differential expression in EJ-shEIF5A2 cells compared with that in EJ-scramble cells by using a human tumour metastasis RT ${ }^{2}$ profiler PCR array. (B) Knockdown of EIF5A2 expression substantially downregulated TGF- $\beta 1$ and upregulated E-cadherin and $\alpha$-catenin expression in EJ-shEIF5A2 cells detected by western blotting. (C) Western blotting shows that after silence of TGF- $\beta 1$ or STAT3 in 5637-EIF5A2 cells, the levels of the epithelial markers (E-cadherin and $\alpha$-catenin) increased, while the levels of the mesenchymal markers (vimentin and fibronectin) decreased. (D) Wound-healing assays show that the enhanced migratory capacity in 5637-EIF5A2 cells was inhibited by silence of TGF- $\beta 1$ or STAT3. (E) The invasive capacity of 5637-EIF5A2 cells was dramatically inhibited after siTGF- $\beta 1$ or siSTAT3 treatment in a transwell assay. (F) Immunofluorescence staining shows an upregulated expression of E-cadherin and $\alpha$-catenin and a downregulated expression of vimentin and fibronectin in 5637-EIF5A2 cells, after knockdown of TGF- $\beta 1$ or STAT3 by specific siRNA. Data are the means \pm s.e. of three independent experiments. ${ }^{*} P<0.05,{ }^{*} P<0.01$ by Student's $t$-test.

subcellular localisation. As shown in Figure 6D, STAT3 localised to both the nucleus and cytoplasm in 5637-vector cells, whereas it was mainly detected in the nucleus of 5637-EIF5A2 cells. The translocation of STAT3 between 5637-vector cells and 5637EIF5A2 cells was confirmed by western blotting analyses of cytoplasmatic and nuclear extracts (Figure 6E). Furthermore, the dual luciferase reporter assay showed that knocking down of STAT3 by specific siRNA partly inhibited the transcriptional activity of EIF5A2 on the TGF- $\beta 1$ promoter (upregulated ratio 4.83 vs 2.05, Figure $6 \mathrm{~F}$ ). Further studies demonstrated that EIF5A2mediated the upregulation of TGF- $\beta 1$ expression, EMT and the migratory/invasive capacity of 5637-EIF5A2 cells were partly prevented, when STAT3 was knocked down (Figure 5).

\section{DISCUSSION}

In this study, the protein expression of EIF5A2 was examined in $\mathrm{BC}$ tissues of 154 localised invasive $\mathrm{BC}$ patients treated with radical cystectomy. We demonstrated that overexpression of EIF5A2 in localised invasive $\mathrm{BC}$ was an independent predictor for poor metastasis-free survival. More important, our molecular mechanisms study showed that EIF5A2 promoted BC aggressiveness by upregulating TGF- $\beta 1$ through STAT3 to induce EMT.

The EIF5A2 gene, located on chromosome 3q26, has been identified as an oncogene (Guan et al, 2001, 2004). Since then, EIF5A2 has been found to be overexpression in diverse human 


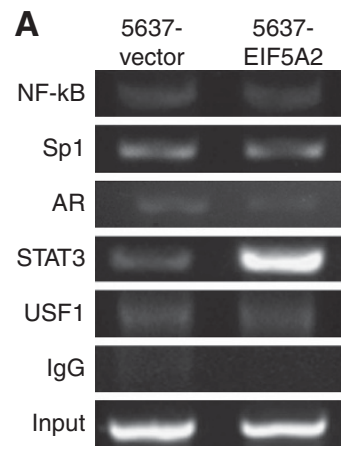

D DAPI

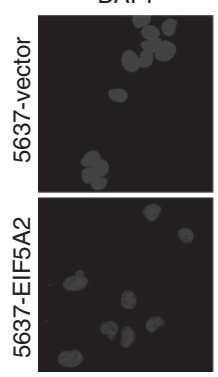

\begin{abstract}
STAT3
\end{abstract}

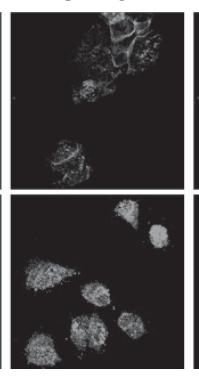

B

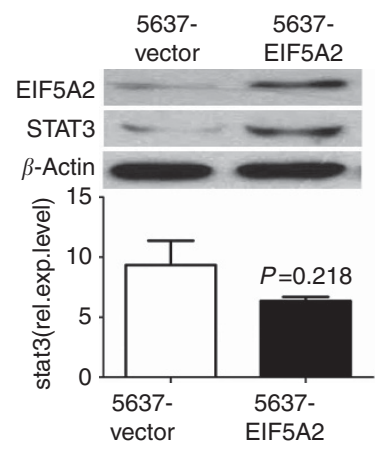

Merge

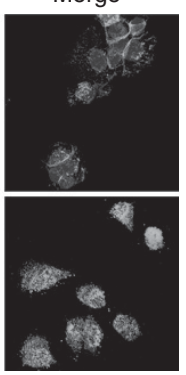

C
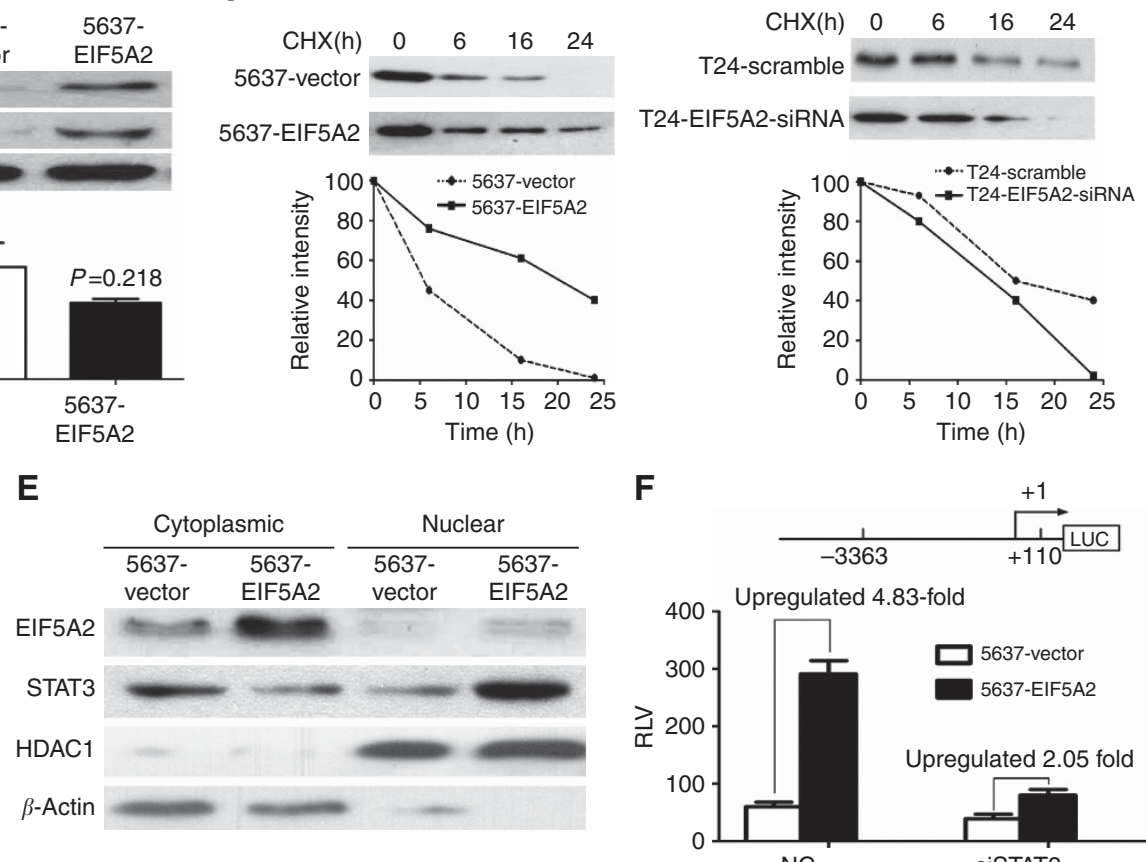

$\mathbf{F}$
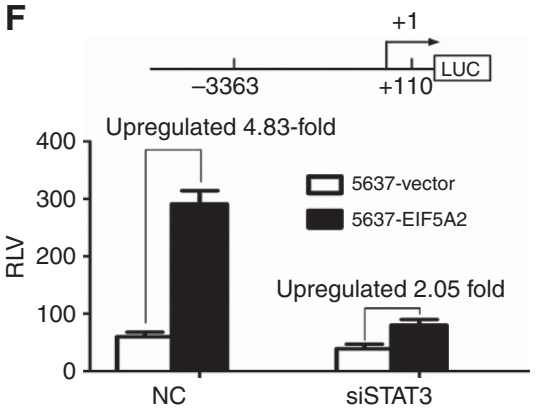

Figure 6. EIF5A2 stabilized STAT3 and stimulated its nucleus localisation to enhance the enrichment of STAT3 onto the TGF- $\beta 1$ promoter. (A) The ChIP assay was performed to analyse the enrichment of NF- $\kappa$ B, Sp1, AR, STAT3, and USF1 on the promoter of TGF- $\beta 1$ between 5637-vector and 5637-EIF5A2 cells. (B) The expression levels of STAT3 in 5637-vector and 5637-EIF5A2 cells were examined by western blotting and GPCR. (C) Half-life analysis of the STAT3 protein. Cells were treated with $20 \mu \mathrm{m}$ cycloheximide for the indicated times and then analysed by western blotting. (D) The effect of EIF5A2 on the subcellular localisation of STAT3 proteins (green) was examined under a fluorescent microscope. (E) Western blotting of cytoplasmatic and nuclear extracts showed the expression of EIF5A2, STAT3, HDAC1, and $\beta$-actin. HDAC1 controls nuclear fractionation. (F) 5637 cells were first transfected with siSTAT3 or control siRNA. After $36 \mathrm{~h}$, the cells were co-transfected with the pGL3-TGF $\beta 1$ promoter luciferase, pRL-TK Renilla luciferase construct and control plasmid pcDNA3.1(+) or pcDNA-EIF5A2 plasmid. Thirty-six hours later, the luciferase activity of the TGF $\beta 1$ promoter was measured and normalised relative to luciferase activity. The bar shows the mean \pm s.d. of three independent experiments. The full colour version of this figure is available at British Journal of Cancer online.

malignancies and is associated with tumour progression, lymph node metastasis and poor prognosis (Marchet et al, 2007; Xie et al, 2008; Yang et al, 2009; Tang et al, 2010; He et al, 2011; Zhu et al, 2012). In this study, univariate and multivariate Cox regression analysis also indicated that EIF5A2 was an independent prognostic factor to metastasis-free survival of patients with localised invasive $\mathrm{BC}$, which was consistent with our previous finding (Chen et al, 2009). To clarify the biological function of EIF5A2 in BC cells, a series of in vitro and in vivo experiments were conducted. The results showed that siRNA mediated EIF5A2 knockdown in T24 and EJ cells, inhibited BC cell to migrate or invade and reduced EMT. On the contrary, it was opposite results in EIF5A2 overexpression 5637 cells. In a tail vein injection mouse model of cancer metastasis, knockdown of EIF5A2 decreased the cancer cells metastatic potential in vivo, while overexpression of EIF5A2 led to a significant increase in the number of lesions of lung metastasis. These data indicated that EIF5A2 induced EMT and promoted aggressiveness in $\mathrm{BC}$ cells.

To investigate the underlying molecular mechanisms involving EIF5A2 and BC EMT and aggressiveness, we compared mRNA expression profiles between EJ-shEIF5A2 cells and EJ-scramble cells using a human tumour metastasis real-time PCR array, containing 84 well-known cell invasion/metastasis-related genes. We found that E-cadherin (i.e. cadherin 1 ), CTNNA1, TGF- $\beta 1$, TIMP2, TIMP3 and TIMP4 genes showed more than a two times change in mRNA levels. Subsequently, upregulation of E-cadherin and $\alpha$-catenin, downregulation of TGF- $\beta 1$ were validated in protein levels by western blotting in EJ-shEIF5A2 cells. In this study, the mRNA expression level of MTA1 in 5637-EIF5A2 cells only slightly elevated by real-time PCR array. However, our previous finding showed that EIF5A2 is responsible for the activation of MTA1 in colorectal carcinoma (Zhu et al, 2012). We conducted western blotting to further confirm the protein expression levels of MTA1 in BC cells. Our western blotting results showed no significant upregulation of MTA1 in 5637-EIF5A2 cells compared with 5637-vector cells (data not shown). The discordance might be explained as the molecular mechanisms by which EIF5A2 regulates cancer cell aggressiveness might be tumour-type special.

TGF- $\beta 1$ promotes tumour progression in advanced stages by inducing tumour invasion, EMT, and metastasis (Massague, 2008). TGF- $\beta 1$ has been demonstrated to have an important role in many cancers cell invasiveness, EMT, and metastasis (Han et al, 2005; Natsuizaka et al, 2010; Zhang et al, 2011; Wendt et al, 2013). Previous studies also reported that TGF- $\beta 1$ is upregulated in BC tissue relative to benign tissue (Eder et al, 1997), and TGF- $\beta 1$ levels are elevated in the plasma and peritoneal fluid of BC patients (Eder et al, 1996; Shariat et al, 2001; Eissa et al, 2007). To determine if TGF- $\beta 1$ is a downstream target involved in EIF5A2-induced BC cell EMT and aggressiveness, we silenced TGF- $\beta 1$ by siRNA in $5637-E I F 5 A 2$ cells. We found that the enhancement of EIF5A2 on migratory/invasive capacities and EMT dramatically vanished when TGF- $\beta 1$ was knocked down. On the other hand, when TGF- $\beta 1$ was introduced in EIF5A2-silenced T24 and EJ cells, the migratory/invasive and EMT phenotypes of BC cells were substantially rescued. These data suggested that TGF- $\beta 1$ might be a critical downstream target of EIF5A2 and was responsible for the EIF5A2-induced EMT and invasiveness in BC cells. 
To date, however, the mechanisms by which EIF5A2 regulates TGF- $\beta 1$ expression have not been elucidated. TGF- $\beta 1$ has been shown to be regulated by transcription factors such as NF- $\kappa \mathrm{B}, \mathrm{Sp} 1$, AR, USF1, and STAT3 in various experimental systems (Kim et al, 1998; Weigert et al, 2004; Ogata et al, 2006; Qi et al, 2008; Lin et al, 2010). In the present study, we did not find the incremental enrichment of NF- $\kappa \mathrm{B}, \mathrm{Sp} 1, \mathrm{AR}$, and USF1 on the promoter of TGF- $\beta 1$; however, the enrichment of STAT3 on the TGF- $\beta 1$ promoter was substantially enhanced after the overexpression of EIF5A2. Subsequently, we observed the upregulation level of STAT3 in 5637-EIF5A2 cells, whereas real-time PCR shows no significant change in STAT3 mRNA. We speculated that the discordance between STAT3 mRNA and protein levels might be explained by EIF5A2 mediated posttranslational modification of STAT3. As our anticipated, our results showed that EIF5A2 stabilized STAT3 and stimulated STAT3 translocation to the nucleus. High protein levels of STAT3 in the nucleus might responsible for the increment binding of STAT3 to the TGF- $\beta 1$ promoter to enhance its transcription. In addition, our luciferase reporter assays showed that silencing of STAT3 by siRNA in 5637EIF5A2 cells only partly inhibited the transcriptional activity of EIF5A2 on the TGF- $\beta 1$ promoter, and EIF5A2-mediated TGF- $\beta 1$ upregulation was partly inhibited by knockdown of STAT3. These data imply that besides STAT3, other unknown mechanisms might be involved in the regulation of TGF- $\beta 1$ by EIF5A2 in BC cells. Clearly, further work is needed to clarify the mechanisms of EIF5A2 regulating TGF- $\beta 1$ in detail.

In summary, we showed that overexpression of EIF5A2 in localised invasive BC was an independent predictor for poor metastasis-free survival. Further molecular mechanisms study revealed that EIF5A2 elevated TGF- $\beta 1$ expression through STAT3 to induce EMT and promote aggressiveness in BC. These findings might potentially help us target a subset of the localised invasive $\mathrm{BC}$ patient population for more aggressive postsurgical adjuvant anticancer therapies. The molecular mechanisms findings might be responsible, at least partly, for the metastatic potential of localised invasive $\mathrm{BC}$.

\section{ACKNOWLEDGEMENTS}

This work was supported by the National Natural Science Foundation of China (81172429, 81372357, 81372730 and 81225018), the Fundamental Research Funds for the Central Universities (09ykpy35), the Science and Information Technology Foundation of Guangzhou (2011J2200065), and the Guangdong Provincial Science and Technology Foundation (2008B030301112 and 2010B031600036).

\section{CONFLICT OF INTEREST}

The authors declare no conflict of interest.

\section{REFERENCES}

Chen W, Luo JH, Hua WF, Zhou FJ, Lin MC, Kung HF, Zeng YX, Guan XY, Xie D (2009) Overexpression of EIF-5A2 is an independent predictor of outcome in patients of urothelial carcinoma of the bladder treated with radical cystectomy. Cancer Epidemiol Biomarkers Prev 18: 400-408.

Eder IE, Stenzl A, Hobisch A, Cronauer MV, Bartsch G, Klocker H (1996) Transforming growth factors-beta 1 and beta 2 in serum and urine from patients with bladder carcinoma. J Urol 156: 953-957.

Eder IE, Stenzl A, Hobisch A, Cronauer MV, Bartsch G, Klocker H (1997) Expression of transforming growth factors beta-1, beta 2 and beta 3 in human bladder carcinomas. Br J Cancer 75: 1753-1760.
Eissa S, Salem AM, Zohny SF, Hegazy MG (2007) The diagnostic efficacy of urinary TGF-beta1 and VEGF in bladder cancer: comparison with voided urine cytology. Cancer Biomark 3: 275-285.

Guan XY, Fung JMW, Ma NF, Lau SH, Tai LS, Xie D, Zhang Y, Hu L, Wu QL, Fang Y, Sham JST (2004) Oncogenic role of eIF-5A2 in the development of ovarian cancer. Cancer Res 64: 4197-4200.

Guan XY, Sham JST, Tang TCM, Fang Y, Huo KK, Yang JM (2001) Isolation of a novel candidate oncogene within a frequently amplified region at 3q26 in ovarian cancer. Cancer Res 61: 3806-3809.

Han G, Lu SL, Li AG, He W, Corless CL, Kulesz-Martin M, Wang XJ (2005) Distinct mechanisms of TGF-beta1-mediated epithelial-to-mesenchymal transition and metastasis during skin carcinogenesis. J Clin Invest 115: 1714-1723.

He LR, Zhao HY, Li BK, Liu YH, Liu MZ, Guan XY, Bian XW, Zeng YX, Xie D (2011) Overexpression of eIF5A-2 is an adverse prognostic marker of survival in stage I non-small cell lung cancer patients. Int J Cancer 129: 143-150.

Jain S, Wei J, Mitrani LR, Bishopric NH (2012) Auto-acetylation stabilizes p300 in cardiac myocytes during acute oxidative stress, promoting STAT3 accumulation and cell survival. Breast Cancer Res Treat 135: 103-114.

Kim Y, Ratziu V, Choi SG, Lalazar A, Theiss G, Dang Q, Kim SJ, Friedman SL (1998) Transcriptional activation of transforming growth factor betal and its receptors by the Kruppel-like factor Zf9/core promoter-binding protein and Sp1. Potential mechanisms for autocrine fibrogenesis in response to injury. J Biol Chem 273: 33750-33758.

Lin WY, Tsai WL, Shao RX, Wu GY, Peng LF, Barlow LL, Chung WJ, Zhang LL, Zhao H, Jang JY, Chung RT (2010) Hepatitis C virus regulates transforming growth factor beta 1 production through the generation of reactive oxygen species in a nuclear factor kappa B-dependent manner. Gastroenterology 138: 2509-2518.

Marchet A, Mocellin S, Belluco C, Ambrosi A, DeMarchi F, Mammano E, Digito M, Leon A, D’Arrigo A, Lise M, Nitti D (2007) Gene expression profile of primary gastric cancer: towards the prediction of lymph node status. Ann Surg Oncol 14: 1058-1064.

Massague J (2008) TGFbeta in cancer. Cell 134: 215-230.

Natsuizaka M, Ohashi S, Wong GS, Ahmadi A, Kalman RA, Budo D, Klein-Szanto AJ, Herlyn M, Diehl JA, Nakagawa H (2010) Insulin-like growth factor-binding protein-3 promotes transforming growth factorbeta 1-mediated epithelial-to-mesenchymal transition and motility in transformed human esophageal cells. Carcinogenesis 31: 1344-1353.

Nguyen DX, Bos PD, Massague J (2009) Metastasis: from dissemination to organ-specific colonization. Nat Rev Cancer 9: 274-284.

Ogata H, Chinen T, Yoshida T, Kinjyo I, Takaesu G, Shiraishi H, Iida M, Kobayashi T, Yoshimura A (2006) Loss of SOCS3 in the liver promotes fibrosis by enhancing STAT3-mediated TGF-beta1 production. Oncogene 25: 2520-2530.

Pelucchi C, Bosetti C, Negri E, Malvezzi M, La Vecchia C (2006) Mechanisms of disease: the epidemiology of bladder cancer. Nat Clin Pract Urol 3: 327-340.

Qi W, Gao S, Wang ZX (2008) Transcriptional regulation of the TGF-beta 1 promoter by androgen receptor. Biochem J 416: 453-462.

Shariat SF, Kim JH, Andrews B, Kattan MW, Wheeler TM, Kim IY, Lerner SP, Slawin KM (2001) Preoperative plasma levels of transforming growth factor beta(1) strongly predict clinical outcome in patients with bladder carcinoma. Cancer 92: 2985-2992.

Siegel R, Naishadham D, Jemal A (2013) Cancer statistics, 2013. CA Cancer J Clin 63: 11-30.

Stenzl A, Cowan NC, De Santis M, Kuczyk MA, Merseburger AS, Ribal MJ, Sherif A, Witjes JA. European Association of U (2011) Treatment of muscle-invasive and metastatic bladder cancer: update of the EAU guidelines. Eur Urol 59: 1009-1018.

Tang DJ, Dong SS, Ma NF, Xie D, Chen LL, Fu L, Lau SH, Li Y, Li Y, Guan XY (2010) Overexpression of eukaryotic initiation factor 5A2 enhances cell motility and promotes tumor metastasis in hepatocellular carcinoma. Hepatology 51: 1255-1263.

Tong ZT, Cai MY, Wang XG, Kong LL, Mai SJ, Liu YH, Zhang HB, Liao YJ, Zheng F, Zhu W, Liu TH, Bian XW, Guan XY, Lin MC, Zeng MS, Zeng YX, Kung HF, Xie D (2012) EZH2 supports nasopharyngeal carcinoma cell aggressiveness by forming a co-repressor complex with HDAC1/ HDAC2 and Snail to inhibit E-cadherin. Oncogene 31: 583-594.

Weigert C, Brodbeck K, Sawadogo M, Haring HU, Schleicher ED (2004) Upstream stimulatory factor (USF) proteins induce human TGF-betal gene activation via the glucose-response element-1013/-1002 in mesangial 
cells: up-regulation of USF activity by the hexosamine biosynthetic pathway. J Biol Chem 279: 15908-15915.

Wendt MK, Schiemann BJ, Parvani JG, Lee YH, Kang Y, Schiemann WP (2013) TGF-beta stimulates Pyk2 expression as part of an epithelialmesenchymal transition program required for metastatic outgrowth of breast cancer. Oncogene 32: 2005-2015.

Xie D, Ma NF, Pan ZZ, Wu HX, Liu YD, Wu GO, Kung HF, Guan XY (2008) Overexpression of EIF-5A2 is associated with metastasis of human colorectal carcinoma. Hum Pathol 39: 80-86.

Yang GF, Xie D, Liu JH, Luo JH, Li LJ, Hua WF, Wu HM, Kung HF, Zeng YX, Guan XY (2009) Expression and amplification of eIF-5A2 in human epithelial ovarian tumors and overexpression of EIF-5A2 is a new independent predictor of outcome in patients with ovarian carcinoma. Gynecol Oncol 112: 314-318.

Zhang HJ, Wang HY, Zhang HT, Su JM, Zhu J, Wang HB, Zhou WY, Zhang H, Zhao MC, Zhang L, Chen XF (2011) Transforming growth factor-beta
1 promotes lung adenocarcinoma invasion and metastasis by epithelial-tomesenchymal transition. Mol Cell Biochem 355: 309-314.

Zheng F, Liao YJ, Cai MY, Liu YH, Liu TH, Chen SP, Bian XW, Guan XY, Lin MC, Zeng YX, Kung HF, Xie D (2012) The putative tumour suppressor microRNA-124 modulates hepatocellular carcinoma cell aggressiveness by repressing ROCK2 and EZH2. Gut 61: 278-289.

Zhu W, Cai MY, Tong ZT, Dong SS, Mai SJ, Liao YJ, Bian XW, Lin MC, Kung HF, Zeng YX, Guan XY, Xie D (2012) Overexpression of EIF5A2 promotes colorectal carcinoma cell aggressiveness by upregulating MTA1 through C-myc to induce epithelial-mesenchymaltransition. Gut 61: $562-575$.

This work is published under the standard license to publish agreement. After 12 months the work will become freely available and the license terms will switch to a Creative Commons AttributionNonCommercial-Share Alike 3.0 Unported License.

Supplementary Information accompanies this paper on British Journal of Cancer website (http://www.nature.com/bjc) 